\title{
Stability of Halophilic Proteins in Hyper Saline Brine: [2Fe-2S] Ferredoxin as a Paradigm
}

\section{Amal K Bandyopadhyay}

Department of Biotechnology, The University of Burdwan, Burdwan, West Bengal, India

*Corresponding author: Amal K Bandyopadhyay, Department of Biotechnology, The University of Burdwan, Burdwan, West Bengal, India, Tel: 9474723882(M); Fax: +91-3422657231; E-mail: akbanerjee@biotech.buruniv.ac.in

Rec date: May 15, 2015; Acc Date: May 20, 2015; Pub date: May 22, 2015

Copyright: (c) 2015 Bandyopadhyay AK. This is an open-access article distributed under the terms of the Creative Commons Attribution License, which permits unrestricted use, distribution, and reproduction in any medium, provided the original author and source are credited.

\begin{abstract}
Apart from normal or mesophilic environment, organisms are found in extreme of salinity, and other hostile environments in the earth. Extreme halophiles thrive as pure culture in their natural environments of saturated salt as other microbes can't venture to grow. Over the evolution, these microorganism grew up with specialized transport-devices to solve the problem of osmoregulation. As a consequence whole of their biochemical machinery started functioning in this highly saline brine situation that mesophile cannot withstand. Intensive researches are thus carried out over the last fifty years to understand salt dependent properties of these proteins and enzymes. Ferredoxin is a small soluble protein that functions as electron carrier in decarboxylation reactions in cytoplasm in conjunction with an oxidoreductase. Two of its representatives from Halobacterium marismortui $(H m F d)$ and Halobacterium salinarum $(H s F d)$ are extensively studied. Atomic structures of $H m F d$ and $H s F d$ reveal that halo adaptation is largely mediated by a hyper acidic inserted domain of some 24 residues long at N-terminus region. By designed kinetics and thermodynamics experiments it was demonstrated that $H s F d$ indeed adapted in high salt and requires $\geq 1.5 \mathrm{M}$ salt to retain its overall structural integrity. While non-specific electrostatic effect is operative at $\leq 0.25 \mathrm{M}$ salt, higher salt promote salt-bridge and hydrophobic stability. At intermediate salt where Hofmeister effects of specific ion interactions are operative, $\mathrm{HsFd}$ forms a hydrophobic collapsed intermediate whose structural properties differs from its native state in saturated salts. Thus intuitively, HsFd in its native state seems to entertain a post Hofmeister like effect in that wide modulation of tertiary interactions might occur.
\end{abstract}

\section{Abbreviations:}

HmFd: Ferredoxin from Halobacterium marismortui; HsFd: Ferredoxin from Halobacterium salinarum; SpFd: Spirulina platensis ferredoxin; $\mathrm{N}_{\mathrm{m}}$ : Native ferredoxin from mesophilic; $\mathrm{U}_{\mathrm{m}}$ : Unfolded ferredoxin from mesophilic; $\mathrm{L}_{\mathrm{h}}$ : Low salt form of $\mathrm{HsFd} ; \mathrm{HC}_{\mathrm{h}}$ : hydrophobic collapse intermediate of halophilic; $\mathrm{HsFd} \mathrm{L}_{\mathrm{h}}$ : Halophilic low salt form; $\mathrm{N}_{\mathrm{h}}$ : Halophilic native state; CSB: Charge screening boarder; HMB: Hofmeister boarder; Post-HMZ: post Hofmeister Zone; HjFd: Haloarcula japonicum Ferredoxin.

\section{Evolutionary Adaption of Halophiles in its Ecological Niche}

"Woesion revolution" [1] demonstrated that the family halobacteriaceae belongs to the archaeal domain of lives. The mechanisms that drive the path of its evolution are substitutions [2] and lateral gene transfers via transformation [3] as high salinity favors better preservation of environmental genetic materials. At the same time in this extreme of salinity, endosysbiosis [4] (and also conjugation) that require a mixed culture state is a rare possibility. Thus, this apparent mode of isolated and desperate evolution seems to make halophiles more advances than prokarya but lag behind the eukarya. This makes the background for its macromolecular structures such as membrane and its lipids composition [5], RNA polymerase [6] and protein synthesis machinery [7] resemble eukarya than bacteria. By the utilization of active transporters [3], iso molarity of saturated salinity is maintained inside and outside the cell in that in the former $\mathrm{K}^{+}$accumulates four time higher than that of $\mathrm{Na}^{+}[2,8]$. This novel strategy of osmoregulation by harbouring high intracellular salt gives rise a fresh set of problems to its proteins, as these conditions are known to interfere with enzyme activity [9], association-dissociation equilibria [10], surface tension [11], relative permeability [12], solubility and overall stability [13] of normal mesophilic proteins. How then haloarchaea solved these problems now that they are deliberate and willing host to high salt in their cytoplasm. This paradox may have a possible resolution to the hypothesis that soluble proteins are adapted but not tolerated to entertain high salt for optimal functionality in an evolutionary time scale and a persistent presence of the same is now necessary for their functionality.

\section{Halophilic Enzymes Show General Mode of Adaptation}

With a view of difficulty in purification of halophilic proteins in high salt and the fact of irreversible denaturation of multimeric enzymes in low salt [14], early studies on halo adaptation were mostly performed by the measurement of enzyme activities on partially or unpurified cell free extracts [15]. These results were then used (i) in halophilic enzymology to classify individual cases into extremely, moderately or poorly halophilic categories [16,17], (ii) in understanding active site stability and eventually (iii) in modeling halo adaption of proteins in general [17]. Analyses of Individual, genome and proteome wide sequence(s) of halophiles provide novel insight into halo adaptation [16-19] in that (a) higher abundance of acidic over basic, (b) lower content of bulky hydrophobic and (c) increase in boarder line hydrophobic residues are observed. 


\section{Ferredoxin as a Probe for Understanding Halo Adaptation}

[2Fe-2S] Ferredoxin in general is a non-heme iron-sulfur protein that acts as in electron carriers in photosynthesis in case of cyan bacteria and green plant [20] and in oxidative decarboxilation reaction in cytoplasm of haloarchaea [21]. Unlike mesophilic ferredoxins $\left(\mathrm{N}_{\mathrm{m}}\right)$, halophilic ones $\left(\mathrm{N}_{\mathrm{h}}\right)$ are constrained for specific interaction with an oxidoreductase (as NADH does) [21] and maintenance of structural integrity in supersaturated salinity conditions (Figure $1, \mathrm{~N}_{h}$ ). The active site is formed by [2Fe-2S] chromophore cofactor and four evolutionary conserved cysteines [20] residues (Figure 1: $A S$ ). Mesophilic representative i.e. $S p F d$ possesses some 98 residues and that in case of $H m F d$ and $H s F d$ are of 128 residues. Apart from signatory difference of 30 residues, main chain topologies of $S p F d$ and $H m F d$ (or $H s F d$ ) remain almost identical with RMSD=1.14 Å2 (Figure 1: A). The extra region in haloarchaea forms 22 and 8 residues long substructures in the $\mathrm{N}$ - (Figure 1, A: region B) and C-terminal end (Figure 1, A: region $\mathrm{B}$ ) respectively [22]. The extra regions were speculated to be due to lateral gene transfer between halobacteria and cysnobacteria [23]. $H m F d$ and $H s F d$ are well studied using sequence [24,25], biochemical [26-29], biophysical [29-31], atomic structural $[22,32]$ and theoretical [33] methods due to their advantages of small size [29], large cellular expression [27] and easy manageable purification from cellular level $[26,29]$ relative to other enzymes [16]. As far as general compositional bias is concerned (see above), halophilic ferredoxins seem to be exceptional and that never encountered in other analyses [17-19]. While overall hydrophobicity and alkalinity remain the same [25], acidic residues shows only $4 \%$ to $5 \%$ excess with drastic decrease in boarder line hydrophobic residues in reference to their mesophilic homologues (unpublished results of $\mathrm{AKB})$.

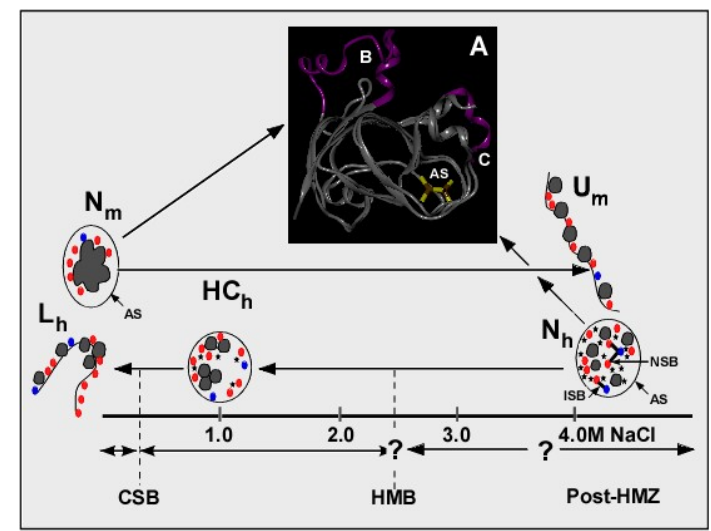

Figure 1: Superposition (A: between $S p F d$ and $H m F d$ ) and model for folded $\left(N_{\mathrm{m}}\right.$ and $\left.N_{\mathrm{h}}\right)$, unfolded $(U m$ and $L h)$ ) and intermediate states $(H C h)$ of mesophilic and halophilic ferredoxins based on literature results. The extra domains ( $B$ and $C$ ) of $H m F d$ are shown in purple colors. The active site is marked by $A S$ where chromophore center is visible. In $N_{\mathrm{h}}$ both networked $(N S B)$ and isolated $(I S B)$ salt bridge are found in the core and on the surface respectively. Unlike compact hydrophobic core in $N_{\mathrm{m}}$, loose hydrophobic (large black circle) core surrounded by acidic (red) and basic (blue) residues along with saturated salt ions (black star) are visible.

\section{Role of N-terminal Insertion Domain in Halo Halophilic}

As far as salt dependent properties and mechanism of adaption are concerned these two representative ferredoxins show wide variations. The observation that $H m F d$ has long term stability at $0.04 \mathrm{M} \mathrm{NaCl}$ [26] and the high resolution crystal structure is devoid of protein-bound salt ions [32], mobile ions mediated shielding of surface charges was denied to be a requirement [34]. In other wards halo adaptation of $H m F d$ is devoid of non-specific electrostatic interactions effects. However, this conjecture was challenged by pioneer continuum electrostatic mediated theoretical studies [33]. Moreover, contention of contribution of salt bridges in halo adaptation of $\mathrm{HmFd}$ was proposed to be due counterbalance effect of the former by [2Fe-2S]chromophore center [28]. However, this does not corroborate with a recent generalized theoretical studies on salt bridges of halophilic proteins [35-37]. Instead, as revealed in the atomic structure [28], a novel mode of stabilization was observed in that except the active site (Figure 1: AS) the entire surface of $\mathrm{HmFd}$ (Figure 1: S) is covered with cluster of negative charges along with the $\mathrm{N}$-terminal hyper acidic domain (Figure 1: B) that are stabilized by $\mathrm{H}$-bonding and dipole interactions contributed by tightly bound hydration shells [31]. A solution structure of $H s F d$ solved at $0.5 \mathrm{M} \mathrm{NaCl}$ shows almost identical main chain topology (RMSD=1.52) as $H m F d$. By novel design of reconstitution experiment it was demonstrated that the halo stability of $H s F d$ is conferred by hyper acidic domain [22] as was entertained in its halophilic cousin. Taken together the adaptation of $\mathrm{HmFd}$ and $H s F d$ was proclaimed to be due to the hyper acidic insertion domain and its preferential acidic substitutions [32,22] but not due to entire protein. Based on the observation, hyper acidic insertion domain of $H j F d$ was considered to be "intrinsic chaperon" that induce folding and chromophore incorporation [28].

\section{Salt Dependent Properties of HsFd and Mechanism of Halo Stability}

\section{Halo stability of HsFd involves two distinct mechanisms: charge screening and hydrophobic effect}

Salt dependent kinetic measurements of HsFd showed a requirement of $\geq 1.5 \mathrm{M} \mathrm{NaCl}$ for maintenance of structural integrity. Loss of tertiary structure, disruption of chromophore center and secondary structures occurs in succession upon withdrawal of salt [29]. Plot of natural logarithm of rate of unfolding (or half-life) against salt concentrations was found to be non-linear indicated involvement of more than one kind of mechanism in this process [38]. While nonspecific electrostatic was considered as the major mechanism of instability in the salt range $0.0-0.25 \mathrm{M}$, salt-solvent mediated perturbation along with specific residue interactions were proposed to be involved in $0.25-1.5 \mathrm{M}$ range.

\section{Salt can't be substituted fully by $\mathrm{H}(+)$ or poly cationic(+++ ....) species}

Detailed equilibrium measurements on $\mathrm{L}_{\mathrm{h}}(0.05 \mathrm{M})$ and $\mathrm{N}_{\mathrm{h}}(4.3 \mathrm{M})$ showed that unlike $\mathrm{N}_{\mathrm{h}}, \mathrm{L}_{\mathrm{h}}$ possesses titratable carboxylates (with up shifted apparent $\mathrm{pKa} \sim 6.0$ ) groups that gain apparent native like stability at low $\mathrm{pH}$ conditions ( $\mathrm{pH} 4.5)$ or by addition of poly cationic but not anionic polymers, clearly indicated charge screening effect [30]. This observation also corroborates with theoretical studies on HmFd [31]. However, midpoint of urea induced transition (i.e. $\mathrm{L}_{\mathrm{h}}$ ? $\mathrm{U}$; 
hence the conformational stability) at low $\mathrm{pH}$ was far less $(\sim 2.0 \mathrm{M})$ than that of the native state (i.e. Nh ?U; $\sim 5.0 \mathrm{M}$ ) suggesting that apart from charge screening effect, high salt also contributes to other mechanisms and that can't be achieved either by lowering the $\mathrm{pH}$ or by addition of poly cationic species into the medium [30].

\section{Salt bridge contributes to overall halo stability of HsFd}

Urea induced unfolding of $\mathrm{N}_{\mathrm{h}}$ (where charge screening is not a possibility) at acidic, neutral and alkaline $\mathrm{pHs}$ were shown to be completely different than that of $\mathrm{L}_{h}$. Relative to the neutral $\mathrm{N}_{h}$, acidic and alkaline ones showed far enhancement of rate of unfolding which was hypothesized to be due to destabilization of crucial salt-bridges in $\mathrm{N}_{h}$ [31]. The following scheme explains possible disruption of salt bridge in presence of acidic and alkaline conditions.

$\mathrm{COOH} \quad \mathrm{NH}_{3}^{(+)} \underset{\text { Acidic }}{\stackrel{\mathrm{H}^{(+)}}{\frac{1}{(-)}}} \mathrm{COO}^{(-)}-\mathrm{NH}_{3}^{(+)} \underset{\text { Alkaline }}{\stackrel{\mathrm{OH}^{(-)}}{\longrightarrow}} \mathrm{COO}^{(-)} \quad \mathrm{NH}_{2}$

\section{At intermediate salt $\mathrm{HsFd}$ has different conformation than native state $(\mathrm{Nh})$}

Unfolding of mesophilic proteins (i.e. $\mathrm{Nm}$ ? U) do not generally involve kinetic intermediates [39]. $H s F d$ functions at cytoplasm at near saturated salt solution $(\geq 4.3 \mathrm{M})$. Has $\mathrm{N}_{\mathrm{h}}$ be at same conformational state as intermediate salt ones that exist below the hypothetical Hofmeister boarder (i.e. $H M B$ but beyond $C S B$; Figure $1)$ ? Salt jump experiments ( $4.3 \mathrm{M}$ ? $1.0 \mathrm{M}, 4.3 \mathrm{M} ? 0.5 \mathrm{M}$ etc) showed kinetics of intermediate salt form follows opposite path (decreasing over time) than the typical unfolding path (increasing over time) at low salt [31]. This intermediate form was thus identified as hydrophobic collapsed intermediate (i.e. $\mathrm{HC}_{\mathrm{h}}$; Figure 1) as it shows ion specific effects in that the effect of anions is greater than cations. Interestingly such ion-specific effect was seen to be absent for the rising unfolding path [31]. However, it is not clear whether $\mathrm{HC}_{\mathrm{h}}$ undergoes local or global collapse. Whatever be the case $\mathrm{HC}_{\mathrm{h}}$ is conformationally different from $\mathrm{N}_{\mathrm{h}}$. Withdrawal of further salt from $\mathrm{HC}_{\mathrm{h}}$, causes production of partially unfolded intermediate (i.e. $\mathrm{L}_{\mathrm{h}}$ ) [31]. $\mathrm{L}_{\mathrm{h}}$ shows short term stability ( $\leq 60 \mathrm{hr}$ at ambient temperature) and eventually precipitates from solution (unpublished results of $\mathrm{AKB}$ ). $\mathrm{HC}_{\mathrm{h}}$ which is observed in the unfolding path of $\mathrm{N}_{\mathrm{h}}$ is evocative of well characterized molten globule state in the folding path of many globular mesophilic proteins [40].

\section{Model for Native $\mathrm{HsFd}$ and Possibility of Post Hofmeister Zone}

At saturated salt, low water activity persist [12] and thus unlike its mesophilic counterpart $\left(\mathrm{N}_{\mathrm{m}}\right)$ where a single tight hydrophobic core is generally observed (Figure 1: $\mathrm{N}_{\mathrm{m}}$ ), a loose hydrophobic core may form in this non-polar like solvent (core of $\mathrm{N}_{\mathrm{h}}$ ). There might also be a possibility of formation of cluster of hydrophobic patches at the vicinity of excessively hydrated negatively charged residues [32]. Identification of locally collapse regions in $\mathrm{HC}_{\mathrm{h}}$ would confirm this assumption. The fact that hydrophobic force is dominant contributor to the native state of protein in general [41] and that in the present case it is weak, alternative weak interactions that are less affected by the presence of multi molar salts might play crucial role in tuning the energetic of $\mathrm{N}_{\mathrm{h}}$ such that the characteristic intricate balance between rigidity and flexibility is achieved. In fact in a recent study it was showed that isolated and networked salt bridges both in protein core and on the surface play critical role in halo stabilization [35]. $\mathrm{N}_{\mathrm{h}}$ also show such interactions (unpublished results of $\mathrm{AKB}$ ). Non-specific classical electrostatic stabilization mediated by mobile ions of bulk solution is the marginal contributor to halo stability of $\mathrm{N}_{\mathrm{h}}[29,30]$.

Non-specific electrostatic interactions possess an upper limit in the salt scale (i.e. CSB in Figure 1). The same could be assumed for Hofmeister effect (specific ion-interactions with protein). If $H M B$ exists then $\mathrm{N}_{\mathrm{h}}$ which function at $4.3 \mathrm{M}$ salt would be beyond of $H M B$ i.e. in post-Hofmeister zone (Figure 1). The existence of post Hofmeister zone (post-HMZ) could not be ruled out by the observation that $H C_{\mathrm{h}}$ (hydrophobically collapsed state) which differ from Nh (hydrophobically relaxed state) is at Hofmeister zone [31]. Again, water activity in intermediate salt is different than saturated one [12]. While verification of $H M B$ and chemistry of interaction of protein-colloid with salt and or water in its post- $H M B$ zone is a matter of intensive research, the existence of the same might bring a generality in exotic nature of all halophilic proteins.

\section{Acknowledgements}

Author is grateful to for the helps of Professor G Krishnamoorthy, Professor RV Hosur, Department of Chemical Science, TIFR and Professor LC Padhy School of Biotechnology KIIT. The active helps of research scholars in my laboratory are thankfully acknowledged. Author is deeply gratitude to his parents and family for their inspiration, affection and love.

\section{References}

1. Woese CR, Fox GE (1977) Phylogenetic structure of the prokaryotic domain: the primary kingdoms. Proc Natl Acad Sci U S A 74: 5088-5090.

2. Eisenberg H, Mevarech M, Zaccai G (1992) Biochemical, structural, and molecular genetic aspects of halophilism. Adv Protein Chem 43: 1-62.

3. Ginzberg M (1978) Energetics and structure of halophilic microorganisms. In: Ginzberg SRCM (eds.) pp 561-577 North-Holand: Elsevior.

4. Lake JA (2009) Evidence for an early prokaryotic endosymbiosis. Nature 460: $967-971$.

5. Blaurock AE, Stoeckenius W, Oesterhelt D, Scherfhof GL (1976) Structure of the cell envelope of Halobacterium halobium. J Cell Biol 71: $1-22$.

6. Zillig W, Stetter KO, Tobien M (1978) DNA-dependent RNA polymerase from Halobacterium halobium. Eur J Biochem 91: 193-199.

7. Chant J, Hui I, Wong DJ Shimmin L, Dennis PP (1989) The protein synthesis Machinery of archaebacterium Halobacterium cutirubrum: Molecular Cheracterization. Syst Appl Microbiol 7: 106-114.

8. Larsen H (1967) Biochemical aspect of halophilism. Adv Microbial Physiol 1: 97-132.

9. Louis BG, Fitt PS (1972) The role of Halobacterium cutirubrum deoxyribonucleic acid-dependent ribonucleic acid polymerase subunits in initiation and polymerization. Biochem J 127: 81-86.

10. Nagy B, Jencks W (1965) Depolymerization of F-Actin by concentrated solutions of salts and denaturing agents. J Am Chem Soc 87: 2480-2488.

11. Nandi PK, Robinson DR (1972) The effects of salts on the free energies of nonpolar groups in model peptides. J Am Chem Soc 94: 1308-1315.

12. Hasted JB, Ritson DM, Collie CH (1948) Dielectric Properties of Aqueous Ionic Solutions. Parts I and II. J Chem Phys 16: 1

13. Hofmeister F (1888) Arch Exp Pathol Pharmakol 24: 247-260 
14. Hecht K, Jaenicke R (1989) Malate dehydrogenase from the extreme halophilic archaebacterium Halobacterium marismortui. Reconstitution of the enzyme after denaturation and dissociation in various denaturants. Biochemistry 28: 4979-4985.

15. Holmes PK, Dundas IE, Halvorson HO (1965) Halophilic enzymes in cell-free extracts of Halobacterium salinarium. J Bacteriol 90: 1159-1160.

16. Lanyi JK (1974) Salt-dependent properties of proteins from extremely halophilic bacteria. Bacteriol Rev 38: 272-290.

17. DasSarma S, Berquist BR, Coker JA, DasSarma P, Müller JA (2006) Postgenomics of the model haloarchaeon Halobacterium sp. NRC-1. Saline Systems 2: 3.

18. Karan R, Capes MD, Dassarma S (2012) Function and biotechnology of extremophilic enzymes in low water activity. Aquat Biosyst 8: 4.

19. Paul S, Bag SK, Das S, Harvill ET, Dutta C (2008) Molecular signature of hypersaline adaptation: insights from genome and proteome composition of halophilic prokaryotes. Genome Biol 9: R70.

20. Hall DO, Cammack R, Rao KK (1971) Role for ferredoxins in the origin of life and biological evolution. Nature 233: 136-138.

21. Kerscher L, Oesterhelt D (1981) The catalytic mechanism of 2-oxoacid: ferredoxin oxidoreductases from Halobacterium halobium. One-electron transfer at two distinct steps of the catalytic cycle. Eur J Biochem 116: 587-94.

22. Marg BL, Schweimer K, Sticht H, Oesterhelt D (2005) A two-alpha-helix extra domain mediates the halophilic character of a plant-type ferredoxin from halophilic archaea. Biochemistry 44: 29-39.

23. Pfeifer F, Griffig J, Oesterhelt D (1993) The fdx gene encoding the [2Fe--2S] ferredoxin of Halobacterium salinarium (H. halobium). Mol Gen Genet 239: 66-71.

24. Hase T, Wakabayashi S, Matsubara H, Mevarech M, Werber MM (1980) Amino acid sequence of $2 \mathrm{Fe}-2 \mathrm{~S}$ ferredoxin from an extreme halophile, Halobacterium of the Dead Sea. Biochim Biophys Acta 623: 139-145.

25. Rao JK, Argos P (1981) Structural stability of halophilic proteins. Biochemistry 20: 6536-6543.

26. Werber MM, Mevarech M (1978) Purification and characterization of a highly acidic $2 \mathrm{Fe}$-ferredoxin from Halobacterium of the dead sea. Arch Biochem Biophys 187: 447-456.

27. Kerscher L, Oesterhelt D, Cammack R, Hall DO (1976) A new plant-type ferredoxin from halobacteria. Eur J Biochem 71: 101-107.
28. Hirota N, Matsuo T, Ikeda A, Yatsunami R, Fukui T, Nakamura S (2005) Role of an N-terminal domain found in the ferredoxin from extremely halophilic archaeon Haloarcula japonicum. J Jap Soc Extremophiles 4: 14-24

29. Bandyopadhyay AK, Sonawat HM (2000) Salt dependent stability and unfolding of [Fe2-S2] ferredoxin of Halobacterium salinarum: spectroscopic investigations. Biophys J 79: 501-510.

30. Bandyopadhyay AK, Krishnamoorthy G, Sonawat HM (2001) Structural stabilization of [2Fe-2S] ferredoxin from Halobacterium salinarum. Biochemistry 40: 1284-1292.

31. Bandyopadhyay AK, Krishnamoorthy G, Padhy LC, Sonawat HM (2007) Kinetics of salt-dependent unfolding of [2Fe-2S] ferredoxin of Halobacterium salinarum. Extremophiles 11: 615-625.

32. Frolow F, Harel M, Sussman JL, Mevarech M, Shoham M (1996) Insights into protein adaptation to a saturated salt environment from the crystal structure of a halophilic 2Fe-2S ferredoxin. Nat Struct Biol 3: 452-458.

33. Elcock AH, McCammon JA (1998) Electrostatic contributions to the stability of halophilic proteins. J Mol Biol 280: 731-748.

34. Ortenberg R, Rozenblatt-Rosen O, Mevarech M (2000) The extremely halophilic archaeon Haloferax volcanii has two very different dihydrofolate reductases. Mol Microbiol 35: 1493-1505.

35. Nayek A, Sen Gupta PS, Banerjee S, Mondal B, Bandyopadhyay AK (2014) Salt-bridge energetics in halophilic proteins. PLoS One 9: e93862.

36. Gupta PS, Mondal S, Mondal B, Islam RN, Banerjee S, et al. (2014) SBION: A Program for Analyses of Salt-Bridges from Multiple Structure Files. Bioinformation 10: 164-166.

37. Gupta PS, Nayek A, Banerjee S, Seth P, Das S, et al. (2015) SBION2: Analyses of Salt Bridges from Multiple Structure Files, Version 2. Bioinformation 11: 39-42.

38. Chiti F, van Nuland NA, Taddei N, Magherini F, Stefani M, et al. (1998) Conformational stability of muscle acylphosphatase: the role of temperature, denaturant concentration, and $\mathrm{pH}$. Biochemistry 37: 1447-1455.

39. Creighton TE (1990) Protein folding. Biochem J 270: 1-16.

40. Agashe VR, Shastry MC, Udgaonkar JB (1995) Initial hydrophobic collapse in the folding of barstar. Nature 377: 754-757.

41. Dill KA (1990) Dominant forces in protein folding. Biochemistry 29: 7133-7155. 